\title{
Electronic Markets on electronic markets in education
}

\author{
Rainer Alt ${ }^{1}$ • Hans-Dieter Zimmermann ${ }^{2}$
}

Published online: 17 October 2016

(C) Institute of Applied Informatics at University of Leipzig 2016

Dear readers of Electronic Markets,

Digital transformation is a universal phenomenon that has the potential to change many industries. Among the well-known examples are the media, travel or retail industry with the financial and automotive industry well underway. By enabling electronic linkages between organizations and customers, information technologies have reduced transaction costs and led to more networked supply chains and entire digital ecosystems. This evolution was described in the editorial of the third issue in 2014, which also proposed two definitions of electronic markets (Alt and Zimmermann 2014): while a narrow conceptualization conceives electronic markets as platforms with price discovery, a wider understanding also includes all electronic applications that enable the networking among organizations and/or customers. Whereas the first interpretation focuses on electronic intermediaries, the second is broader and also covers portals as well as systems for electronic ordering or customer service and solutions for electronic data interchange among organizations. Since the 1980s a wide body of literature has emerged that aims to understand and design the possibilities as well as the effects of electronic markets. Today, electronic platforms are the backbone of many digital business models since their topology allows to link a variety of mobile, social and/or business applications. For example, business models of

Rainer Alt

rainer.alt@uni-leipzig.de

Hans-Dieter Zimmermann

hansdieter.zimmermann@fhsg.ch

1 Information Systems Institute, Leipzig University, 04109 Leipzig, Germany

2 FHS St. Gallen, University of Applied Sciences, Rosenbergstrasse, 59, 9001 St. Gallen, Switzerland

the sharing economy would not be feasible without centralized user registries, catalogs, coordination or trust mechanisms.

\section{Digital transformation in academic publishing}

However, academic research and education on digital transformation is only one side of the coin. The other is the digital transformation of academia itself. In a series of three editorial papers Electronic Markets has already analyzed the existing situation and possible future developments in the area of academic publishing:

The first focus was on reviewing (Alt et al. 2015), which is regarded a key element for assessing the quality or value of academic work. An inflation in the number of academic outlets - journals as well as conferences - corresponds to the key role of publications in academic qualification processes and leads to an increased number of reviews that are necessary. Although knowledge on process management has been widespread since the 1990s, review processes have often remained long and little transparent. Applying the principles of process management also to review processes has been proposed as one measure in this editorial, which might at least be a contribution to relieve reviewers and authors from poorly organized review processes. Electronic platforms for handling manuscripts, which are offered by academic publishers provide a lever for defining and managing these processes.

The second focus was on self-archiving (Alt et al. 2016b) and the growing possibilities to disseminate academic knowledge. Instead of hiding new research insights behind the paywalls of publishing houses, the emergence of open access journals, document servers and electronic publishing platforms, such as ResearchGate, has created new ways in academic publishing. At the same time, publishing platforms also 
allow researchers to enhance their visibility and their reputation via various scores.

This leads to the third focus, which was on quantitative measures in academic publishing, especially the impact factor (Alt et al. 2016a). Based on certain calculation schemes these metrics aim to reflect the relevance of a specific publication and sometimes also the impact of researchers. Various databased from publishers and other organizations - only recently Thomson Reuters sold its business unit around the impact factor to Clarivate Analytics for USD $3.55 \mathrm{bn}$. - established (electronic) services that determine scores, which researchers and/or universities may use in their decision-making. However, the paper also revealed measuring problems and suggested that available metrics should be applied carefully and in appropriate combinations. While more sophisticated measures deem necessary, these have to face the challenge of all standards, i.e. their value grows with the adoption within their target user group.

\section{Digital transformation in academic education}

From the perspective of a higher education organization, publishing is part of the core process of "research", while the other core process is usually "teaching and learning". In addition, similar to cross-functional processes within private sector companies, higher education organizations also have to provide "resource management" activities, such as human resources, accounting and corporate communications (Alt and Auth 2010, 188). Being aware of differences between organizations in the private and in the education sectors, the differences regarding the stage of digital transformation in both sectors are striking. While academics have extensively covered the private sector with research on inter-organizational systems (IOS), electronic commerce and/or electronic business, the education sector has received only little attention. This is particularly striking if one considers that the vast majority of researchers are working in higher education institutions worldwide, and are involved, besides research, in teaching as well as in administrating institutes or faculties. A similar picture is apparent when comparing the evolution of internal information systems in both sectors.

In another previous editorial paper (Alt and Zimmermann 2014) five phases were distinguished (see Fig. 1), which characterized the evolution of integrated information systems in the private sector. These are typically referred to as "Enterprise Resource Planning" (ERP) systems and aim at establishing an integrated view of core business processes and resources of a firm. In the beginning of the 1990s they emerged from systems with a focused functional scope, such as material requirements planning (MRP) or manufacturing resource planning (MRP II) systems. Since ERP systems provided an integrated view across departments, new cross-functional processes could be designed using business process redesign. Driven by internet technologies this phase of internal integration was followed by an increasing integration with stakeholders outside the company, i.e. suppliers and customers using electronic commerce as well as supply chain and customer relationship management modules. Finally, the advantages in service-oriented architectures and cloud computing allowed the use of ERP functionalities by multiple organizations and today we witness a growing integration with technologies, such as the internet of things and big data.

In comparison, the evolution of applying information systems in the education sector shows a considerable delay. Although there might be earlier pioneers, it was only in the 2000s that a broader movement towards more integrated systems could be observed. In analogy to ERP systems, these systems have become known as "Campus Management Systems" (CMS) in the European region and as "Student Information Systems" (SIS) in the Anglo-American community. These systems are often developed as packaged solutions by dedicated software providers and replace functionally focused solutions that were often developed in-house by many education institutions. Similar to the introduction of ERP systems, many CMS projects also faced the challenges of (re)designing cross-functional processes and responsibilities within the respective institutions. This was the prerequisite of pursuing more customer- (or student-) orientation, which allowed to offer services along the entire student life cycle (Alt and Auth 2010, 188). Following this thinking, the relevant CMS activities range from information and application, enrollment, student records, teaching and course management, evaluations to alumni relationships. A move towards more external integration could be observed in the publishing area (open access publications (OA), in particular) and digital platforms for education, while the development of shared services where universities use joint functionalities is only about to emerge. The same applies to

Time

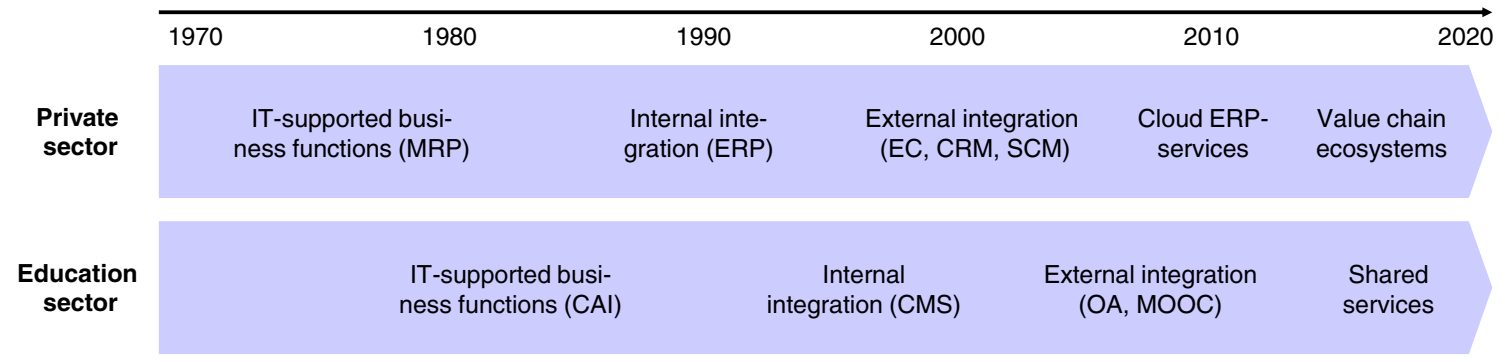

Fig. 1 Delay between the private and the education sector 
the digital transformation itself as noted by Neil Selwyn in his research on digital universities: "while digital technologies are now undoubtedly an embedded future of universities, we need to also acknowledge that they have not yet led to a widespread renewal of higher education. Indeed, despite a superficial hightech sheen, the institutional essence of most universities could be said to remain remarkably intact from "pre-digital' times." (Selwyn 2014, p. 6).

\section{Digital platforms for education}

While many universities are in the process of introducing more encompassing internal CMS systems, digital transformation has made inroads in one area that falls under the CMS concept, but, due to the involved complexity, is often implemented via separate systems that are linked via interfaces (e.g. for identity management). Referred to as electronic learning (E-Learning) systems or as educational technology they aim at "facilitating learning and improving performance by creating, using, and managing appropriate technological processes and resources." (Robinson et al. 2007, 15). So called computer-assisted instruction (CAI) systems date back to the 1960s when one of the first CAI systems was developed at the University of Illinois. For example, the system PLATO (Programmed Logic for Automatic Teaching Operations) sought to produce cost-efficient instruction using inexpensive networked terminals and a simplified programming language for instruction (Van Meer 2003). As a distributed system, PLATO ran on mainframe computers supporting graphics terminals globally. The PLATO system pioneered online forums, message boards, e-mail, chat rooms, instant messaging, remote screen sharing, as well as multiplayer games (Robinson et al. 2007) and was operational until 2006.

With the advent of the World Wide Web, the term Learning Management Systems (LMS) was introduced as an umbrella term used for a wide range of information systems that organize and provide access to online learning services for students and lecturers as well as administrators. Nowadays, LMS are mostly web-based and either provided as a software-as-a-service (SaaS) solution or installed at the institutions' premises. Several solutions are available, such as Moodle ${ }^{1}$ or Google Classrooms. ${ }^{2}$ The latest development in LMS are "Massive Open Online Courses" (MOOCs) intended to provide large-scale online educational programs distributed via electronic platforms, such as coursera. org, ${ }^{3}$ based on cloud computing technologies. LMS that aim to host a MOOC require capabilities to facilitate the exchange of respective e-learning content. Standards, such as the Sharable Content Object Reference Model (SCORM), emerged for that

\footnotetext{
${ }^{1}$ See www.moodle.org

2 See classroom.google.com

${ }^{3}$ See www.coursera.org
}

purpose. ${ }^{4}$ Clearly, these developments increase the ubiquitous accessibility of knowledge as well as the modularization of courses, which may be combined more flexibly beyond the classical physical limitations of an educational institution.

In summary, electronic market platforms are an important driver in the digital transformation of higher education. Among the examples are platforms for publications, for learning content and administrative processes (e.g. enrollment). Surprisingly these systems have received attention in publication outlets targeting the educational communities (see Seufert and Meier 2016), but have only scarcely been addressed in the broader information systems literature, such as Electronic Markets. The brief overview illustrates that learnings from research on IOS, electronic business and the like undertaken in the context of the private sector could also prove to be valuable for the education sector. In particular, shaping a common inter-organizational information infrastructure is the basis for redesigning inter-organizational processes and for reducing redundant systems as well as processes in the education sector. It could be a similar situation as in the private sector some 15 years ago where "billions and billions could be saved if companies collaborated and shared the processes that are now essentially redundant." (Champy 2002, p. 26f).

\section{General research issue}

In fact, two papers of the present general research issue address developments in the education sector. Both contributions were part of the special issue call for papers on "Electronic Markets and the Future Internet: from Clouds to Semantics", which was organized by Ricardo ColomoPalacios (Østfold University College, Norway), Francisco José García-Peñalvo (University of Salamanca, Spain), Robert D. Tennyson (University of Minnesota, USA) and Tokuro Matsuo (Tokyo Metropolitan University, Japan). These colleagues did not only contribute in drafting the call for papers, but also along the entire review process.

The first paper is a position paper authored by Pathak (2016) on "Emerging online educational models and the transformation of traditional universities". Based on well-known literature from the electronic markets area, such as information goods theory and online retailers and marketplaces literature in information systems, the article presents three types of emerging educational business models, which link to the narrow as well as to the wider conceptualization of electronic markets mentioned above: online education marketplaces (OEM), online education providers (OEP), and online education services (OES). Furthermore, the author also suggests a roadmap for the transformation of traditional universities. One of the author's main

\footnotetext{
${ }^{4}$ SCORM was introduced in 2000 and provides a collection of standards and specifications for web-based electronic educational content provision (See scorm.com).
} 
messages supports our observations made above, i.e. that knowledge and experiences in the area of electronic commerce is helpful when investigating the educational sector.

The second paper in the higher education context is titled "Factors propelling the adoption of m-learning among students in higher education" and authored by Yeap et al. (2016). They address $\mathrm{m}$ (obile)-learning and aim to understand the factors of $\mathrm{m}$-learning adoption among university students in developing countries. Therefore, the authors applied and replicated an existing model of mobile learning readiness. As result, all three constructs of attitude, subjective norm and perceived behavioral control had a significant and positive influence on the intention to adopt m-learning, whereupon subjective norm had the strongest impact. In terms of the research's practical implications, the authors propose that social media's networking effects should be used to advocate the benefits of m-learning.

The remaining three papers of this general research issue investigate the role of users on electronic market platforms as socio-technical systems in different application settings. The first is authored by Hariharan et al. (2016) and examines the nature of the decision processes underlying human bidding behavior in auctions. Titled "Think, feel, bid: the impact of environmental conditions on the role of bidders' cognitive and affective processes in auction bidding", the paper comprises an experimental setting to measure how the cognitive workload and emotional arousal were correlated with bidding behavior, compared to the optimal bid. The results help to understand the tradeoff between auction format and bidding performance as well as the role of time pressure in Dutch and first-price sealed-bid auction formats.

In the fourth paper, Koch and Bierbamer (2016) focus on the impact of user innovations on the success of video games. In their research "Opening your product: impact of user innovations and their distribution platform on video game success" the authors collected secondary data for 204 video games from multiple sources and applied them to their research model comprising six hypotheses. The video game's success was measured via user ratings and led to findings on the role of platform support in the distribution of user innovations.

Finally, the paper "The impact of consumer preferences on the accuracy of collaborative filtering recommender systems" authored by Köhler et al. (2016) introduces a microeconomic model that enables the evaluation of recommender systems with regard to different structures of consumer preferences. Instead of analyzing existing markets, the authors present a theoretical analysis of the general effects of different features of the structure of consumers' preferences via simulations. As a main result the authors reveal that the structure of consumers' preferences has a considerable effect on the accuracy of recommender systems in practice.
We hope you enjoy reading this issue and welcome research as well as position papers on the exciting topic of electronic markets in (higher) education.

Your EM Team in Leipzig and St. Gallen

\section{References}

Alt, R., \& Auth, G. (2010). Campus management system. Business \& Information Systems Engineering, 2(3), 187-190. doi:10.1007 /s12599-010-0105-9.

Alt, R., \& Zimmermann, H.-D. (2014). Editorial 24/3: Electronic Markets and general research. Electronic Markets, 24(3), 161-164. doi:10.1007/s12525-014-0163-9.

Alt, R., Militzer-Horstmann, C., \& Zimmermann, H.-D. (2015). Electronic Markets on reviewing. Electronic Markets, 25(4), 255261. doi:10.1007/s12525-015-0207-9.

Alt, R., Militzer-Horstmann, C., \& Zimmermann, H.-D. (2016a). Electronic Markets on the impact factor. Electronic Markets, 26(2), 95-101. doi: 10.1007/s12525-016-0222-5.

Alt, R., Militzer-Horstmann, C., \& Zimmermann, H.-D. (2016b). Electronic Markets on self-archiving. Electronic Markets, 26(1), 1-5. doi: 10.1007/s12525-015-0215-9 .

Champy, J. (2002). X-engineering the corporation: reinventing your business in the digital age. New York (NY): Warner.

Hariharan, A., Adam, M. T. P., Teubner, T., \& Weinhardt, C. (2016). Think, feel, bid: the impact of environmental conditions on the role of bidders' cognitive and affective processes in auction bidding. Electronic Markets, 26(4). doi:10.1007/s12525-0160224-3.

Koch, S., \& Bierbamer, M. (2016). Opening your product: impact of user innovations and their distribution platform on video game success. Electronic Markets, 26(4). doi:10.1007/s12525-0160230-5.

Köhler, S., Wöhner, T., \& Peters, R. (2016). The impact of consumer preferences on the accuracy of collaborative filtering recommender systems. Electronic Markets, 26(4). doi:10.1007/s12525-016-0232-3.

Pathak, B. K. (2016). Emerging online educational models and the transformation of traditional universities. Electronic Markets, 26(4). doi:10.1007/s12525-016-0223-4.

Robinson, R., Molenda, M., \& Rezabek, L. (2007). Facilitating learning. In A. Januszewski \& M. Molenda (Eds.), Educational technology: a definition with commentary (2nd ed., pp. 15-48). Routledge.

Selwyn, N. (2014). Digital technology and the contemporary university: degrees of digitization. Abingdon, New York: Routledge.

Seufert, S., \& Meier, C. (2016). From eLearning to digital transformation: a framework and implications for $\mathrm{L} \& \mathrm{D}$. International Journal of Advanced Corporate Learning, 9(2), 27-33. doi:10.3991 /ijac.v9i2.6003.

Van Meer, E. (2003). PLATO: from computer-based education to corporate social responsibility. Iterations an Interdisciplinary Journal of Software History, 2(1), 1-22.

Yeap, J. A. L., Ramayah, T., \& Soto-Acosta, P. (2016). Factors propelling the adoption of m-learning among students in higher education. Electronic Markets, 26(4). doi:10.1007/s12525-015-0214-x. 